\title{
Synthesis and Structural, Magnetic and EPR Characterization of Discrete Finite Antiferromagnetic Chains
}

\author{
Michael L. Baker • Marzio Rancan • Floriana Tuna • \\ Grigore A. Timco • David Collison • Hannu Mutka • \\ Hans-Ulrich Güdel • Robin J. Pritchard • \\ Richard E. P. Winpenny • Eric J. L. McInnes
}

Received: 15 May 2009/Revised: 15 June 2009/Published online: 15 November 2009

(C) Springer 2009

\begin{abstract}
The synthesis, magnetic and electron paramagnetic resonance (EPR) characterisation of isolated, discrete, $\left\{\mathrm{Cr}_{n}^{\mathrm{III}}\right\}$ antiferromagnetically coupled chain complexes is reported for $n=6$ and 7. Previous studies had reported supramolecular linked $\left\{\mathrm{Cr}_{n}^{\mathrm{III}}\right\}_{x}$ species. For $n=6$, the lowest lying total spin state is diamagnetic with $S=1$ and 2 first and second excited states, respectively; for $n=7$, the lowest lying total spin state is $S=3 / 2$ with $S=1 / 2$ and $5 / 2$ first and second excited states, respectively. The zero-field splittings of these states are well defined by low-temperature, multi-frequency EPR spectroscopy.
\end{abstract}

\section{Introduction}

The chemistry and physics of antiferromagnetically coupled rings (AF rings) discrete molecular, cyclic transition-metal clusters with AF coupling between adjacent metal ions-have received much attention. Early examples [1, 2] were

Dedicated to Prof Dr Wolfgabg Lubitz on the occasion of his 60th birthday.

Electronic supplementary material The online version of this article (doi:10.1007/s00723-009-0063-x) contains supplementary material, which is available to authorized users.

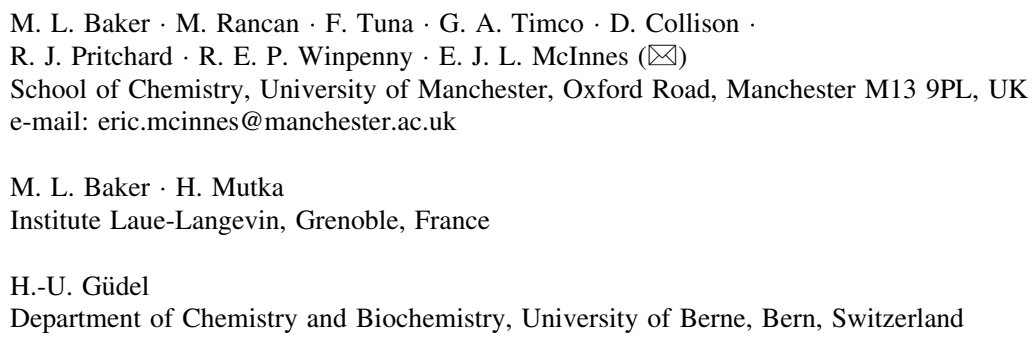




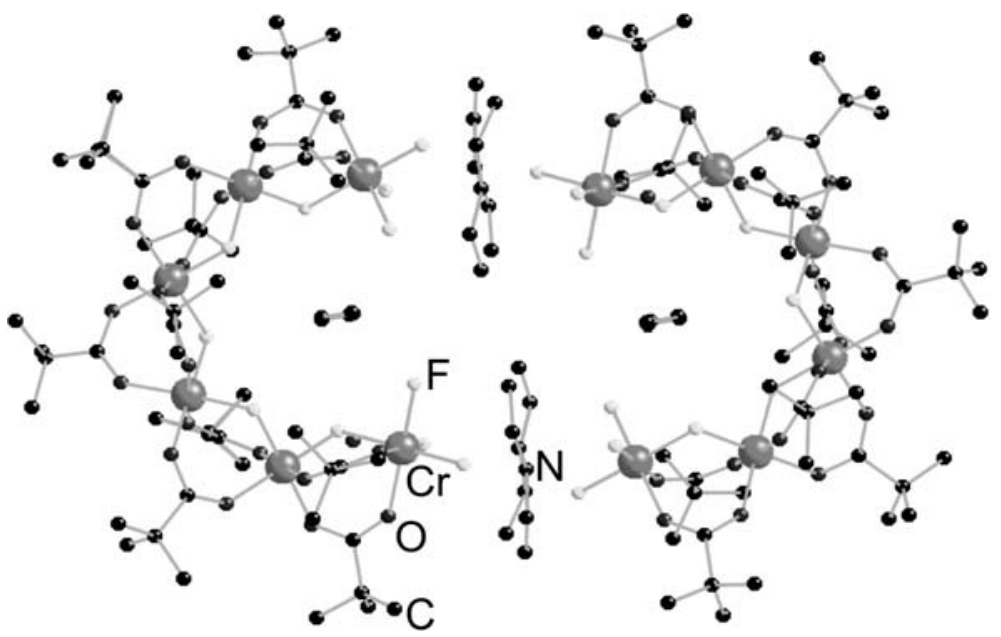

Fig. 1 Structure of $\left[\left(\mathrm{Et}_{2} \mathrm{NH}_{2}\right)_{3}\left\{\mathrm{Cr}_{6} \mathrm{~F}_{11}\left(\mathrm{O}_{2} \mathrm{CCMe}_{3}\right)_{10}\right\}\right]_{2}$. Scheme: $\mathrm{Cr}$ (large spheres), $\mathrm{F}$ (small light spheres), $\mathrm{O}$ (grey), $\mathrm{C}$ (black), $\mathrm{H}$ omitted for clarity

proposed as models for one-dimensional (1-D) antiferromagnets and they have provided macroscopic systems for investigation of fundamentally important quantum phenomena, e.g., coherence and tunnelling effects [3-7]. Odd-electron examples have been proposed as "qubits" in quantum information processing $[6,7]$. AF chain complexes - discrete, finite open structures - are much rarer [8], but their physics has also been of interest in, for example, understanding the nature of magnetic ground states and excitations in spin clusters, and termination effects in 1-D AF materials. We recently reported $\left\{\mathrm{Cr}_{n}^{\mathrm{III}}\right\}$ AF chains of formula $\left[\mathrm{Cr}_{n} \mathrm{~F}_{n+5}\left(\mathrm{O}_{2} \mathrm{CCMe}_{3}\right)_{2 n-2}\right]^{3-}$ $(n=3,6$ and 7) [8,9], and their magnetic properties as probed by magnetic susceptibility, electron paramagnetic resonance (EPR) and inelastic neutron scattering (INS). Families such as these are particularly important since they allow detailed comparison of different chain lengths of otherwise identical species. However, in each case the discrete $\left\{\mathrm{Cr}_{n}\right\}$ units, which are curved, oligomerized into the supramolecular species $\left[\left(\mathrm{R}_{2} \mathrm{NH}_{2}\right)_{3}\left\{\mathrm{Cr}_{n} \mathrm{~F}_{n+5}\left(\mathrm{O}_{2} \mathrm{CCMe}_{3}\right)_{2 n-2}\right\}\right]_{x}(n=6, x=2$ or 4; $n=7, x=2$ ) bound by H-bonding between terminal fluorides at the chain termini and bridging alkylammonium cations (e.g., Fig. 1).

There were some ambiguities in the analysis of their magnetic and spectroscopic data [8]: it was necessary to invoke two different $\mathrm{Cr}$-. Cr exchange interactions (terminal and internal) in $\left\{\mathrm{Cr}_{6}\right\}_{2}$ but not $\left\{\mathrm{Cr}_{7}\right\}_{2}$; fourth-order zero-field splitting (ZFS) and strain effects were necessary to model EPR of the low-lying spin states; there were discrepancies in ZFS as determined by EPR and INS. It remained a possibility that interchain interactions were responsible and, indeed, Monte Carlo simulation of susceptibility data for $\left\{\mathrm{Cr}_{6}\right\}_{4}$ found a ferromagnetic interchain exchange $\left(2 J_{\text {inter }} \sim+1 \mathrm{~cm}^{-1}\right)$ of the magnitude similar to the ZFS parameters [8]. In order to probe whether these effects are inherent to the chains or are due to interchain effects we report here genuinely isolated $\left\{\mathrm{Cr}_{6}\right\}$ and $\left\{\mathrm{Cr}_{7}\right\}$ chains and their characterization by magnetometry and multi-frequency EPR spectroscopy. The structure of $\left\{\mathrm{Cr}_{6}\right\}$ has been reported in Ref. [9]. 

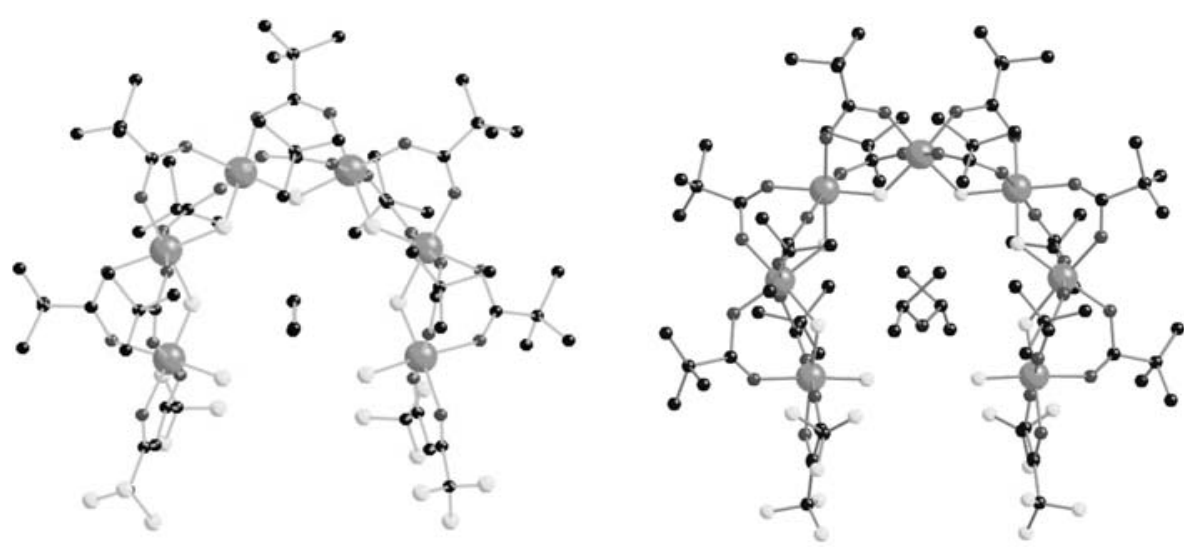

Fig. 2 The crystal structures of $\left(\mathrm{Et}_{2} \mathrm{NH}_{2}\right)\left[\mathrm{Cr}_{6} \mathrm{~F}_{7}\left(\mathrm{O}_{2} \mathrm{CCMe}_{3}\right)_{10}(\mathrm{hfac})_{2}\right] \quad(\mathbf{1} ; \quad$ left $)$ and $\left({ }^{\mathrm{i}} \mathrm{Pr}_{2} \mathrm{NH}_{2}\right)\left[\mathrm{Cr}_{7} \mathrm{~F}_{8}\left(\mathrm{O}_{2} \mathrm{CCMe}_{3}\right)_{12}(\mathrm{hfac})_{2}\right](2 ;$ right $)$

\section{Materials and Methods}

Compound 1 was prepared as reported previously [9]. To synthesize the compound 2, a solution of $\left\{\left[{ }^{\mathrm{i}} \mathrm{Pr}_{2} \mathrm{NH}_{2}\right]_{3}\left[\mathrm{Cr}_{7} \mathrm{~F}_{12}\left(\mathrm{O}_{2} \mathrm{CCMe}_{3}\right)_{12}\right]\right\}_{2}(0.21 \mathrm{mmol})$ and 1,1,1,5,5,5hexafluoro-2,4-pentanedione (Hhfac, $2.10 \mathrm{mmol}$ ) in $\mathrm{CH}_{2} \mathrm{Cl}_{2}(30 \mathrm{ml})$ was stirred and refluxed for $4 \mathrm{~h}$. The solvent was removed and $\mathbf{2}$ was isolated by column chromatography (silica gel with 1:10 EtOAc/hexane; $\mathbf{2}$ is the first product). Crystals were obtained from EtOAc/ $\mathrm{CH}_{3} \mathrm{CN}$ (1:1) after 1 day (27\% yield). Elemental analysis, found: $\mathrm{Cr}, 16.47 ; \mathrm{C}, 41.02 ; \mathrm{H}, 5.98 ; \mathrm{N}, 0.67 \%$. Calculated for $\mathrm{C}_{76} \mathrm{H}_{126} \mathrm{Cr}_{7} \mathrm{~F}_{20} \mathrm{NO}_{28}$ : Cr, 16.21; C, 40.65; H, 5.66; N, 0.62\%. Electrospray mass spectroscopy (tetrahydrofuran $[\mathrm{THF}]-\mathrm{MeOH}$, run in $\mathrm{MeOH}) \mathrm{m} / z:-2,143[\mathrm{M}-$ $\left.\left({ }^{\mathrm{i}} \mathrm{Pr}_{2} \mathrm{NH}_{2}\right)\right]^{-},+2,347\left[\mathrm{M}+\left({ }^{\mathrm{i}} \mathrm{Pr}_{2} \mathrm{NH}_{2}\right)\right]^{+}$.

Crystal data for 2: $\mathrm{C}_{76} \mathrm{H}_{124} \mathrm{Cr}_{7} \mathrm{~F}_{20} \mathrm{NO}_{28}$, monoclinic, $C 2 / c, a=25.040(7)$, $b=20.533(4), \quad c=24.218(6) \AA, \quad \beta=101.899(11)^{\circ}, \quad V=12184(5) \AA^{3}, \quad M=$

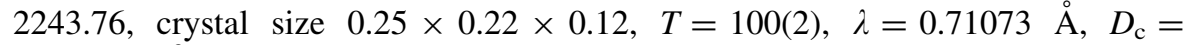
$1.223 \mathrm{~g} / \mathrm{cm}^{3}, Z=4,11736$ reflections collected, 5043 independent $\left(R_{\text {int }}=0.145\right)$, $R(\mathrm{~F})=0.1200$ for $I>2 \sigma(\mathrm{I})[\mathrm{wR} 2=0.2892$ for all data $]$.

Magnetic data were measured on a Quantum Design XL7 superconducting quantum interference device (SQUID) magnetometer. Q- and W-band EPR spectra were recorded on Bruker EMX and Elexsys spectrometers. $\chi_{M}$ and $M$ were calculated using MAGPACK [10]. EPR simulations were performed using Weihe's SIMEPR program [11].

\section{Results and Discussion}

The isolated chains are made from their dimeric counterparts: reaction of $\left[\left(\mathrm{R}_{2} \mathrm{NH}_{2}\right)_{3}\left\{\mathrm{Cr}_{n} \mathrm{~F}_{n+5}\left(\mathrm{O}_{2} \mathrm{CCMe}_{3}\right)_{2 n-2}\right\}\right]_{2}$ with the $\beta$-diketone Hhfac gives $\left(\mathrm{R}_{2} \mathrm{NH}_{2}\right)$ $\left[\mathrm{Cr}_{n} \mathrm{~F}_{n+1}\left(\mathrm{O}_{2} \mathrm{CCMe}_{3}\right)_{2 n-2}(\mathrm{hfac})_{2}\right]\left(\mathbf{1}: n=6, R=\right.$ Et [9]; 2: $n=7, R={ }^{\mathrm{i}} \operatorname{Pr}$, Fig. 2) in good yield. The only significant difference between their structures and those of 

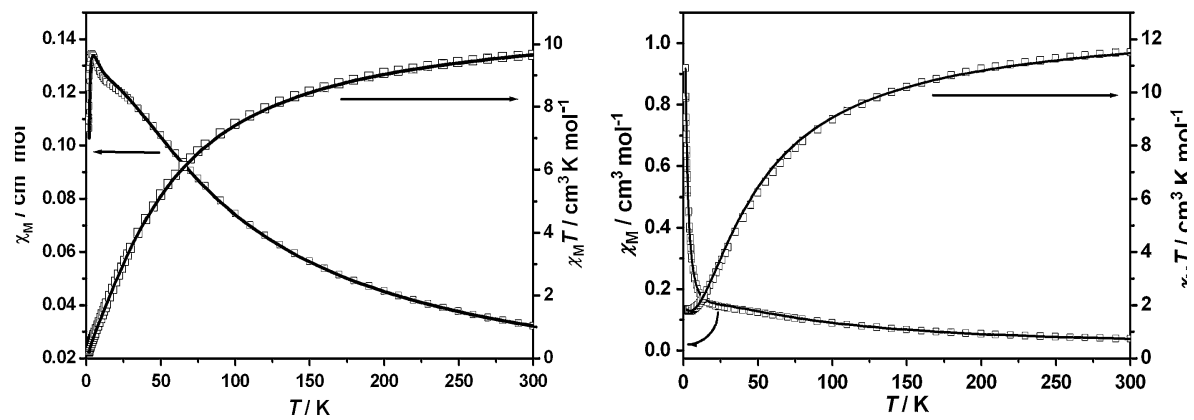

Fig. $3 \chi_{\mathrm{M}}$ and $\chi_{\mathrm{M}} T$ versus $T$ data (open squares) for $\mathbf{1}$ (left) and $\mathbf{2}$ (right) with fits using the parameters in the text (solid lines). Applied field, $1000 \mathrm{G}$

$\left\{\mathrm{Cr}_{n}\right\}_{x}$ is the presence of a chelating diketonate on the metal ions at the chain termini (replacing terminal fluorides), thus disrupting the $\mathrm{H}$-bonding and isolating the chains. The cation sits in the center of the curved "horseshoe" anion in each case.

The magnetic behaviors of $\mathbf{1}$ and $\mathbf{2}$ are both characteristic of AF intrachain coupling (Fig. 3). $\chi_{\mathrm{M}}(T)$ and $\chi_{\mathrm{M}} T(T)\left(\chi_{\mathrm{M}}=\right.$ molar magnetic susceptibility) can be modelled on the basis of the isotropic spin Hamiltonian Eq. (1), where $J_{1}$ and $J_{2}$ are the "terminal" and "internal" $\mathrm{Cr} \cdots \mathrm{Cr}$ exchange interactions, respectively.

$$
\mathrm{H}=-2 J_{1}\left(S_{1} \cdot S_{2}+S_{n-1} \cdot S_{n}\right)-2 J_{2} \sum_{i=2}^{n-1} S_{i} \cdot S_{i+1}+\mu_{B} B \sum_{i=1}^{n} g_{i} \cdot S
$$

Best fits are with $J_{1}=-5.58 \mathrm{~cm}^{-1}, J_{2}=-7.25 \mathrm{~cm}^{-1}$ and $g=1.98$ for $\mathbf{1}$, and $J_{1}=J_{2}=-5.6 \mathrm{~cm}^{-1}$ with $g=1.98$ for 2 (Fig. 3). A simple model with $J_{1}=J_{2}$ is satisfactory for 2 , but introduction of $J_{1} \neq J_{2}$ best reproduces the low-temperature shoulder and peak in $\chi_{\mathrm{M}}(T)$ for $\mathbf{1}$. The calculated level schemes for these parameters are shown in Fig. 4: 1 has an $S=0$ ground state with $S=1\left(3.4 \mathrm{~cm}^{-1}\right)$ and 2 $\left(12.5 \mathrm{~cm}^{-1}\right)$ first excited states; 2 has an $S=3 / 2$ ground state with $S=1 / 2$ $\left(6.5 \mathrm{~cm}^{-1}\right)$ and $5 / 2\left(14.6 \mathrm{~cm}^{-1}\right)$ first excited states. The ground states are consistent with the low-temperature limiting values of $\chi_{\mathrm{M}} T\left(\sim 0\right.$ and $1.83 \mathrm{~cm}^{3} \mathrm{~K} / \mathrm{mol}$ for 1 and 2 , respectively), and the magnetisation $(M)$ versus the applied field $(B)$ behaviour at low temperature (Figure S1). For 2, $M(B)$ saturates at $2.97 \mu_{\mathrm{B}}$; for $\mathbf{1}, M(B)$ at $2 \mathrm{~K}$ has a point of inflection characteristic of a change in the ground state from $S=0$ to $S=1$ on increasing $B$.

In order to probe the lowest lying states directly we use EPR spectroscopy. Wellresolved spectra are observed below ca. $30 \mathrm{~K}$ (e.g., Fig. 5 and S2) even from neat powders. For $\mathbf{2}$, low-temperature Q- and W-band spectra are both dominated by the $S=3 / 2$ ground state which can be modelled with $D=-0.50,|E|=0.07 \mathrm{~cm}^{-1}$ and $g_{\text {iso }}=1.97$ (Fig. 6; $D$ and $E$ are the axial and rhombic ZFS parameters with the usual definitions). At both frequencies the $S=1 / 2$ first excited state is also observed at $g=1.97$. This is more prominent at Q- than at W-band since the $S=3 / 2$ ground state is stabilised cf. the $S=1 / 2$ excited state in higher applied fields. 

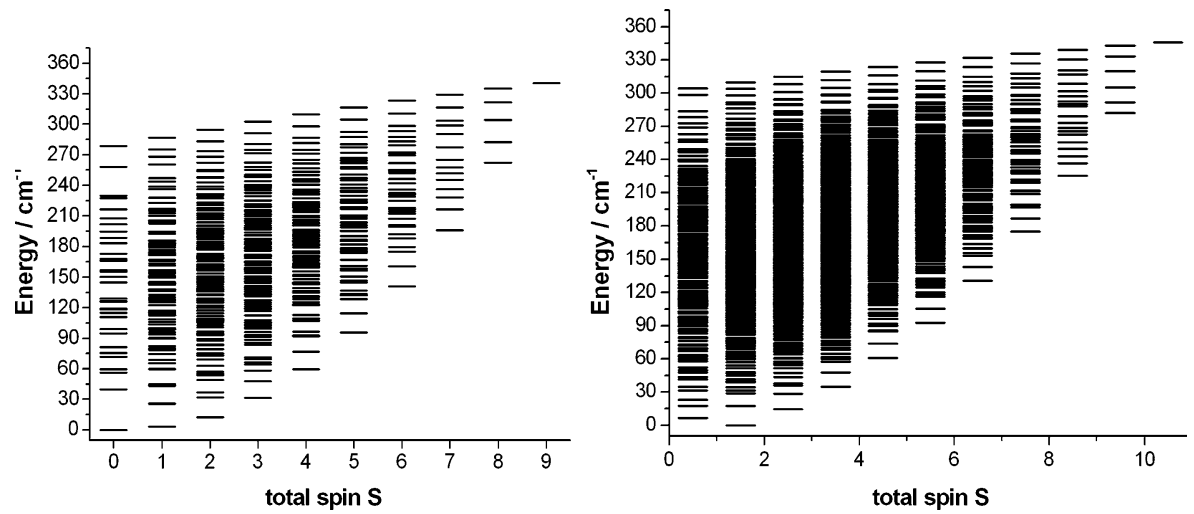

Fig. 4 Eigenvalues of spin Hamiltonian Eq. (1) for compounds 1 (left) and $\mathbf{2}$ (right) using the $J$-values in the text

Fig. 5 Variable-temperature Q-band EPR spectra of a powder sample of compound $\mathbf{1}$

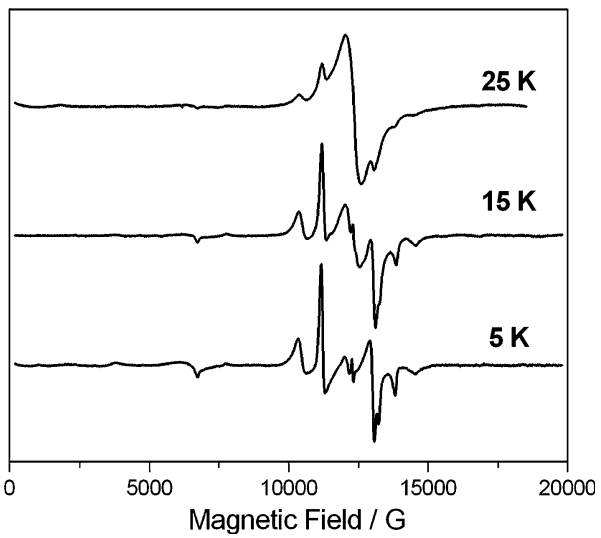

For 1, we observe features from the $S=1$ and 2 first and second excited states, respectively (Fig. 7). ${ }^{1}$ The intense "half-field" transition and the low-amplitude features between 20-30 and 40-50 kG at W-band are characteristic of a rhombic spin triplet: simulation gives $D=+1.0,|E|=0.17 \mathrm{~cm}^{-1}$ with $g_{x, y}=1.98$, $g_{z}=1.97$ (Fig. 7, left). With these parameters there are few features of the triplet observable at Q-band and this spectrum is dominated by the $S=2$ second excited state (Fig. 7, right). Therefore, we have modelled this state from Q-band data. We were unable to simulate the spectrum simply on the basis of the second-order ZFS parameters $D$ and $E$. In order to keep the model as simple as possible we restricted

\footnotetext{
${ }^{1}$ The spectra were summed to match the maximum amplitude of the "allowed" transitions from each spin state. Inadequacies in the line widths and shapes of the simulated spectra make an accurate weighting using the susceptibility-determined state separations difficult. However, the relative intensities are of the correct order.
} 


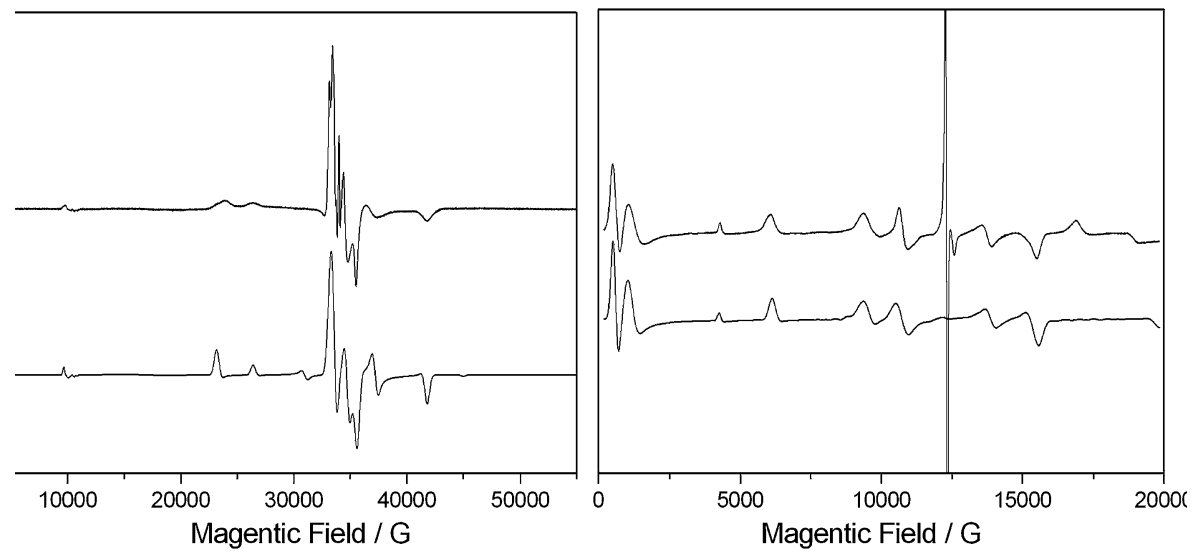

Fig. $6 \mathrm{~W}$ - (left; ca. $94 \mathrm{GHz}$ ) and Q-band (right; ca. $34 \mathrm{GHz}$ ) EPR spectra of a powdered sample of compound 2 (restrained in eicosane) at $5 \mathrm{~K}$ (upper spectra), and simulations of the $S=3 / 2$ ground state with the parameters in the text (lower spectra). The intense feature at ca. $12.5 \mathrm{kG}$ at Q-band is the $S=1 / 2$ first excited state
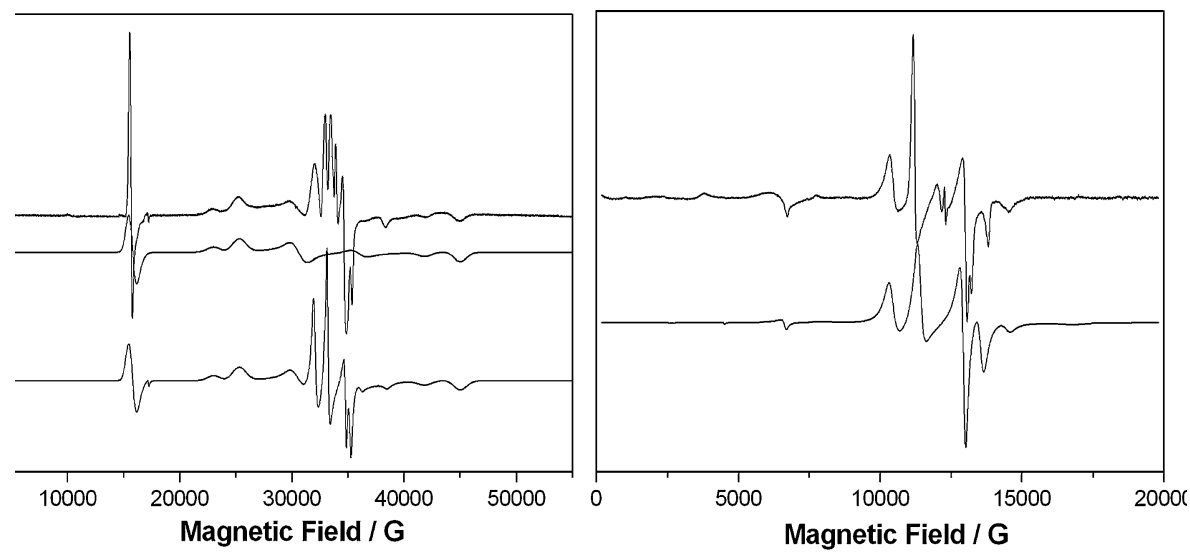

Fig. 7 Left W-band EPR spectrum of a powder of compound 1 (restrained in eicosane) at $5 \mathrm{~K}$ (top). Simulations of $S=1$ state (middle) and sum of $S=1$ and 2 states (bottom) with the parameters in the text. Right Q-band spectrum (top) and simulation of $S=2$ state (bottom)

ourselves to adding a single (axial) fourth-order term $B_{4}^{0 .}{ }^{2}$ It was also necessary to include $D$-strain (ca. 10\%) to reproduce the broadening of "outer" versus "inner" transitions apparent in Fig. 5, right. The best fit gives $D=+0.130, E=0$, $B_{4}^{0}=+2 \times 10^{-4} \mathrm{~cm}^{-1}$ with $g_{\text {iso }}=1.96$. These parameters also reproduce the majority of the central features in the $\mathrm{W}$-band spectrum. At both frequencies there are two additional transitions near $g=2$ which we believe originate from higher

\footnotetext{
${ }^{2}$ The fourth-order operator is defined as: $\hat{O}_{4}^{0}=35 \hat{S}_{z}^{4}-[30 S(S+1)-25] \hat{S}_{z}^{2}+3 S^{2}(S+1)^{2}-6 S(S+1)$.
} 
excited states; this is supported by their different temperature dependences (Figs. 5 and S2).

In summary, the magnetic and EPR data are consistent with the integer and halfinteger states, and dia- and paramagnetic ground states, expected for $n=$ odd and even AF chains of $S=3 / 2 \mathrm{Cr}^{\mathrm{III}}$ ions. Analysis shows that the inequality $J_{1} \neq J_{2}$ found necessary to fit the susceptibility data for $\left\{\mathrm{Cr}_{6}\right\}_{2}$ using spin Hamiltonian Eq. (1) is not due to interchain effects. However, EPR shows that there is a substantial ZFS $\left(|D|=1.0 \mathrm{~cm}^{-1}\right)$ of the lowest paramagnetic state, which lies only ca. $3 \mathrm{~cm}^{-1}$ above the $S=0$ ground state in zero field. ${ }^{3}$ Therefore, use of the isotropic spin Hamiltonian Eq. (1) is probably not valid for these compounds at low temperature, and use of $J_{1} \neq J_{2}$ may simply be masking anisotropy effects; we are currently investigating this. The fourth-order ZFS terms necessary to model the $S=2$ second excited state of $\left\{\mathrm{Cr}_{6}\right\}_{x=1,2}$ also appears to be an inherent effect. Such terms in exchange-coupled clusters can be indicative of mixing between different $S$-states $[12,13]$, due to anisotropic terms that are neglected in Eq. (1). We have recently observed such effects in low-lying excited states of the related $\left\{\mathrm{Cr}_{7} \mathrm{M}\right\}$ family of $\mathrm{AF}$ ring compounds $(\mathrm{M}=$ divalent metal ion), where nonnegligible anisotropic exchange interactions were found to be important in addition to local ZFS [14]. We are currently studying the isolated $\left\{\mathrm{Cr}_{6}\right\}$ and $\left\{\mathrm{Cr}_{7}\right\}$ systems by INS and a full global analysis of the EPR, INS and susceptibility data to a common set of parameters in the uncoupled basis will be reported later.

Acknowledgments We are grateful to the European Commission Network of Excellence MagMaNet (Molecular Approach to Nanomagnets and Multifunctional Materials), the Engineering and Physical Sciences Research Council, and to the Institute Laue Langevin for funding.

\section{References}

1. K.L. Taft, C.D. Delfs, G.C. Papefthymiou, S. Foner, D. Gatteschi, S.J. Lippard, J. Am. Chem. Soc. 166, 823 (1994)

2. J. van Slageren, R. Sessoli, D. Gatteschi, A.A. Smith, M. Helliwell, R.E.P. Winpenny, A. Cornia, A.-L. Barra, A.G.M. Jansen, E. Rentschler, G.A. Timco, Chem. Eur. J. 8, 277 (2002)

3. O. Waldmann, Coord. Chem. Rev. 249, 2550 (2005)

4. M. Affronte, E.J.L. McInnes, S. Piligkos, G.A. Timco, R.E.P. Winpenny, Coord. Chem. Rev. 249, 2577 (2005)

5. D. Gatteschi, R. Sessoli, J. Villain, Molecular Nanomagnets, chap. 14. (Oxford University Press, Oxford, 2006)

6. M. Affronte, S. Carretta, G.A. Timco, R.E.P. Winpenny, Chem. Commun. pp. 1789-1797 (2007)

7. F. Meier, J. Levy, D. Loss, Phys. Rev. Lett. 90, 047901 (2003)

8. S.T. Ochsenbein, F. Tuna, M. Rancan, R.S.G. Davies, C.A. Muryn, O. Waldmann, R. Bircher, A. Sieber, G. Craver, H. Mutka, F. Fernandez-Alonso, A. Podlesnyak, L.P. Engelhardt, G.A. Timco, H.U. Güdel, R.E.P. Winpenny, Chem. Eur. J. 14, 5144 (2008)

9. M. Rancan, G.N. Newton, C.A. Muryn, R.G. Pritchard, G.A. Timco, L. Cronin, R.E.P. Winpenny, Chem. Commun. pp. 1560-1562 (2008)

10. J.J. Borrás-Almenar, J.M. Clemente-Juan, E. Coronado, B.S. Tsukerblat, J. Comput. Chem. 22, 985 (2001)

\footnotetext{
${ }^{3}$ The ZFS parameters for the lowest paramagnetic states of $\mathbf{1}$ and $\mathbf{2}$ as determined by EPR are in excellent agreement with values observed directly by INS (unpubl.).
} 
11. J. Glerup, H. Weihe, Acta Chem. Scand. 45, 444 (1991)

12. A. Wilson, J. Lawrence, E.C. Yang, M. Nakano, D.N. Hendrickson, S. Hill, Phys. Rev. B 74, 140403 (2006)

13. S. Accorsi, A.-L. Barra, A. Caneschi, G. Chastanet, A. Cornia, A.C. Fabretti, D. Gatteschi, C. Mortalò, E. Olivieri, F. Parenti, P. Rosa, R. Sessoli, L. Sorace, W. Wernsdorfer, L. Zobbi, J. Am. Chem. Soc. 128, 4742 (2006)

14. S. Piligkos, H. Weihe, E. Bill, F. Neese, H. El Mkami, G.M. Smith, D. Collison, G. Rajaraman, G.A. Timco, R.E.P. Winpenny, E.J.L. McInnes, Chem. Eur. J. 15, 3152 (2009) 